\title{
Four scenarios
}

\section{R Gillon}

\section{Promoting respect for the four principles remains of great practical importance in ordinary medicine}

$\square$ he following are four "scenarios" with brief outlines of how Raanan Gillon has analysed them using the "four principles" approach. These are the four cases that the commentators were asked to analyse.

Professor Gillon has for many years advocated the use of the Beauchamp and Childress four principles approach as a widely and interculturally acceptable method for medical ethics analysis (he has called himself their unpaid European agent). At present there seems to be a backlash by some bioethicists against this approach, with among others, adherents of feminist ethics, narrative ethics, virtue ethics, and various varieties of regional ethics claiming to offer better approaches to medical ethics.

At Raanan Gillon's request this special issue of the Journal of Medical Ethics is intended to focus on this aspect of his work, with a view not only to discussing the issue of how different approaches to medical ethics are and/or are not compatible with the four principles approach but also to make clear to JME readers what alternative ethics analysis method is preferred and used by the various commentators.

\section{THE "STANDARD" JEHOVAH'S WITNESS CASE}

In the first scenario, that of the "standard" Jehovah's Witness case, a competent adult patient loses a massive amount of blood from a blood vessel bleeding in an acute duodenal ulcer. The best chance of saving his life is an urgent blood transfusion along with operative intervention to arrest the bleeding. The patient refuses blood but asks for treatment instead with the best available non-blood products, and surgery, accepting the substantial risk that surgery without blood transfusion is much less likely to save his life than surgery with blood transfusion. Raanan Gillon analyses this case along standard four principles lines, and concludes: that the patient's wishes ought to be respected because, briefly summarised, the patient's autonomy is thus respected, the patient's own assessment of harms and benefits for himself in addition leads the patient to conclude that far more harm over benefit would result for him from a life saving blood transfusion than from death without a blood transfusion, without countervailing overall harm and benefit assessments overruling this personal assessment; that rights based justice and legal justice allow him to refuse even life prolonging treatment, and that though non-blood alternative treatments may be more expensive than blood transfusions, they are not so disproportionately more expensive that it would be wrong to use them if available-and if they were disproportionately expensive he would be prepared to forgo them.

\section{THE "STANDARD" CHILD OF A JEHOVAH'S WITNESS CASE}

A 2 year old infant has lost a massive amount of blood in a road accident and again the best chance of saving the child's life is an urgent blood transfusion and operative intervention to arrest the bleeding. Both the child's parents are Jehovah's Witnesses and refuse to give permission for a blood transfusion, requesting instead that the best available non-blood products are used to restore volume and that surgery is carried out without blood. They understand that this will be a far more dangerous course of action than surgery plus blood transfusion but persist in refusing permission for a blood transfusion for their child. The surgeon in charge tells them there is no time to argue about the issue, and he is cross matching blood for transfusion and will administer the blood against the parent's instructions in order to save the child's life. He has instructed the hospital's lawyer to try to obtain urgent court approval of his action, and they are welcome to argue their case with the court but he intends to transfuse the child unless a rapid decision by a judge forbidding him to do so is produced in time to prevent him. Raanan Gillon analyses this case using what he has described as the "four principles plus scope" approach, concluding that the surgeon, if he cannot obtain parental consent to save the child's life is morally right (and probably legally right) to override their refusal and administer a blood transfusion on the grounds (briefly summarised) that the child does not fall within the scope of the principle of respect for autonomy, and that the parents' authority to decide on medical treatment for their child morally should not and legally does not extend to imposing severe and probably fatal harm on their child in the pursuit of their own religious beliefs rather than in what their society, though not their religion, regards as the child's best interests. ${ }^{2}$

\section{SELLING KIDNEYS FOR TRANSPLANTATION}

Should people be allowed to sell a kidney for transplantation? Raanan Gillon uses the four principles approach to argue that while in individual cases it may be entirely morally justified, respecting individuals' autonomy (both donors/sellers and recipients), producing net benefit over harm for donors/sellers and recipients, and involving at least no transgression of rights based justice, enhancing distributive justice, and in countries that have not banned it involving no transgression of legal justice, none the less overall the likely dangers of financial exploitation and of postoperative harm to predominantly poor donors/sellers, the likely increased risks to recipients of HIV and other infections, and the likely reduction in volunteer donors, will probably result in sufficient excess overall of harm over benefit for him to conclude that a legal ban would be justified.

\section{GENETIC MANIPULATION TO PRODUCE GERMLINE TRANSMISSIBLE GENETIC ENHANCEMENT}

Arguing against current moral and legal bans on genetic enhancement and germline transmission of genetic modifications, Raanan Gillon offers a "thought experiment" example to support his case (incidentally defending the importance of "thought experiments" in moral thinking, especially in the context of new and rapidly developing genetic science and technology). He imagines the development of a genetic manipulation technique that allows the introduction of a gene conferring resistance to the AIDS virus, HIV. First it is introduced successfully as a somatic intervention, affecting only the individual treated. This would be genetic enhancement, but would be no more morally unacceptable than current methods of vaccination, which are also enhancement interventions, in that they enhance people's normal abilities to resist infections. Then a technique, successfully tested in primates, is developed that allows the resistance gene to be transmitted in pregnancy to the developing human fetus. The resulting offspring would be resistant to AIDS and would 
transmit this resistance to their offspring and so on indefinitely. If such a technique had been shown to be safe in animal experiments I argue, using the four principles approach, that the technique should be accepted for clinical testing by willing and informed volunteers, even though it would involve both genetic enhancement and germline transmissibility. As with other examples, he also points out that by giving a different "weighting" to the conflicting principles it is possible to come to different conclusions, despite accepting the same prima facie principles. ${ }^{4}$

J Med Ethics 2003;29:267-268

Author's affiliation

R Gillon, Imperial College London, UK

Correspondence to: Professor R Gillon, Centre for Primary Care and Social Medicine Ethics Unit, Imperial College London, Charing Cross Campus, Reynolds Building, St Dunstan's Road, London W6 8RP, UK;

raanan.gillon@imperial.ac.uk

\section{REFERENCES}

1 Gillon R. Medical ethics: four principles plus attention to scope. BM 1994:309:184-8.

2 Gillon R. Primum non nocere in paediatrics. In: Burgio G, Lantos J, eds. Primum non nocere today-a symposium on paediatric ethics. Excerpta medica international congress series 1073. Amsterdam: Elsevier, 1994

3 Gillon R. Transplantation and ethics. In: Thomasma D, Kushner T, eds. From birth to death-science and bioethics. Cambridge: Cambridge University Press, 1996.

4 Gillon R. Health care ethics, the four principles and the new genetics. In: Cooper DN, ed. The nature encyclopaedia of the human genome (vol 3). London: Macmillan, Nature Publishing Group, 2003: 180-4.

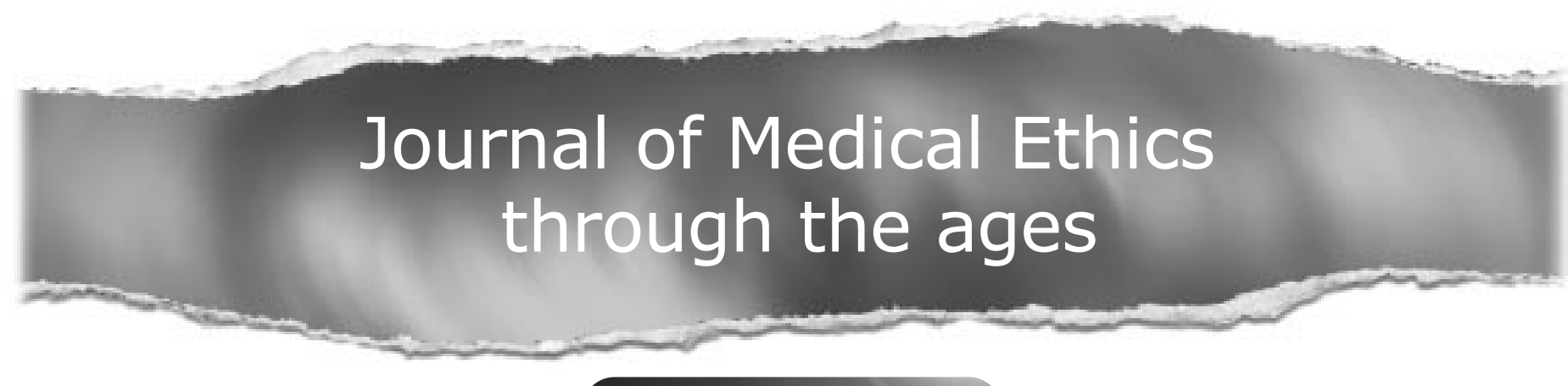

Browse the Archive

Journal of Medical Ethics online has an archive of content dating back to 1975.

Full text from 2000; abstracts from 1975.

www.jmedethics.com 